\title{
Effectiveness of Educational Program on Knowledge Regarding Safe Handling of Cancer Drugs among Staff Nurses
}

\author{
Geetha Chockalingam
}

\begin{abstract}
Background and objectives: Cancer is a group of disease which comprises of more than 200 diseases. They are considered as a disease of the aged; although the majority of cases that is about (77\%) cases are diagnosed to have cancer at the age of 55 years. The study aimed to assess the effectiveness of educational program on knowledge regarding safe handling of cancer drugs among staff nurses.

Materials and methods: A quantitative research approach is adopted with the pre-experimental (one group pre-test post-test only) research design and convenient sampling technique was used to select the sample and structured questionnaire was used to collect the data among 60 staff nurses working in Mahatma Gandhi Medical College Research Institute, Puducherry. The pre-test was conducted by using structured questionnaire and the educational program (power point) was implemented to staff nurses regarding safe handling of cancer drugs. The posttest was conducted after 7 days of pre-test.

Results: The results shown that the effectiveness of educational program on knowledge regarding safe handling of cancer drugs between the pre-test and post-test, the $p$ value was highly significant at $p<0.001$ level.

Conclusion: It was implied that educational program regarding safe handling of cancer drugs was effective.

Keywords: Cancer, Educational program, Safe handling of cancer drugs.

Pondicherry Journal of Nursing (2019): 10.5005/jp-journals-10084-12109
\end{abstract}

\section{INTRODUCTION}

Cancer is a group of disease which comprises of more than 200 diseases. They are considered as a disease of the aged, as the majority of patients (77\%) diagnosed to have cancer are at the age of 55 years. It occurs in people of all ages, including children. However, there is significant variations in incidence of different types of cancer and it depends on the age, sex, geographical variation, heredity and so many other factors. ${ }^{2,3,5}$

Globally cancer accounts for $5.1 \%$ of total disease and $12.5 \%$ of all deaths. In 2016, it was estimated to have 1,685,210 new cases of cancer in the US. In Puducherry the number of old cases in JIPMER hospital was 13,277 and the new case accounted for $1,116 .{ }^{1}$ The hazardous effects of cancer drugs that they not only affect the cancer patients, but also harm the staff nurses who handle these drugs during their administration and disposal..$^{9-11}$

The nursing personnel should know how to handle the hazardous materials for safeguarding themselves, protect the patients and staff members. ${ }^{13}$ Nurses are the key person in cancer care unit and basically they require knowledge about handling of cancer drugs. ${ }^{17,19}$ These safety precautions include identification of patient, preparation of drugs, verification and documentation of the administering cancer drugs, use of personal protective equipment; transport the chemotherapeutic agents, supplies and handling skill. ${ }^{14-16}$

The conceptual framework for this study was derived from general system theory ${ }^{6,7}$ (Ludwig von Bertalanffy, 1968).

\section{Objectives}

- To assess the level of knowledge regarding safe handling of cancer drugs among staff nurses working in selected hospital.

- To evaluate the effectiveness of educational program regarding safe handling of cancer drugs among staff nurses working in selected hospital.
Department of Child Health Nursing, Kasturba Gandhi Nursing College, Sri Balaji Vidyapeeth, Puducherry, India

Corresponding Author: Geetha Chockalingam, Department of Child Health Nursing, Kasturba Gandhi Nursing College, Sri Balaji Vidyapeeth, Puducherry, India, Phone: +91 8807788796, e-mail: geethakasii@gmail.com

How to cite this article: Chockalingam G. Effectiveness of Educational Program on Knowledge Regarding Safe Handling of Cancer Drugs among Staff Nurses. Pon J Nurs 2019;12(1):11-12.

Source of support: Nil

Conflict of interest: None

- To find out the association between the knowledge regarding safe handling of cancer drugs with selected demographic variables of staff nurses.

\section{Hypotheses}

- $\mathrm{H}_{1}$-There is a significant difference in pre-test and post-test level of knowledge regarding safe handling of cancer drugs among staff nurses.

- $\mathrm{H}_{2}$-There is a significant association between the level of knowledge regarding safe handling of cancer drugs and selected demographic variables of staff nurses.

\section{Materials and Methods}

A quantitative research approach was adopted with the preexperimental (one group pre-test post-test only) research design. ${ }^{4,8}$ This study was conducted among 60 staff nurses working in Mahatma Gandhi Medical College Research Institute, Puducherry. Convenient sampling technique was used to select the samples. The pre-test was conducted by using structured questionnaire and the educational program was implemented to

(O) The Author(s). 20190pen Access This article is distributed under the terms of the Creative Commons Attribution 4.0 International License (https://creativecommons. org/licenses/by-nc/4.0/), which permits unrestricted use, distribution, and non-commercial reproduction in any medium, provided you give appropriate credit to the original author(s) and the source, provide a link to the Creative Commons license, and indicate if changes were made. The Creative Commons Public Domain Dedication waiver (http://creativecommons.org/publicdomain/zero/1.0/) applies to the data made available in this article, unless otherwise stated. 
Table 1: Distribution of level of knowledge regarding safe handling of cancer drugs during pre-test and post-test $(n=60)$

\begin{tabular}{|c|c|c|c|c|c|}
\hline \multirow[b]{2}{*}{ S. no. } & \multirow[b]{2}{*}{ Level of knowledge } & \multicolumn{2}{|c|}{ Pre-test } & \multicolumn{2}{|c|}{ Post-test } \\
\hline & & $n$ & $\%$ & $n$ & $\%$ \\
\hline 1 & Adequate knowledge ( $\geq 75 \%)$ & 2 & 3.3 & 55 & 91.7 \\
\hline 2 & Moderately adequate knowledge $(50-<75 \%)$ & 22 & 36.7 & 5 & 8.3 \\
\hline 3 & Inadequate knowledge $(<50 \%)$ & 36 & 60 & 0 & 0 \\
\hline
\end{tabular}

Table 2: Mean, median, standard deviation, mean difference, pre-test and post-test comparison value of the knowledge regarding safe handling of cancer drugs $(n=60)$

\begin{tabular}{lrcllll}
\hline Knowledge & Mean & Median & SD & Mean difference & t test & $p$ value \\
\hline Pre-test & 8.62 & 8 & 2.969 & 7.917 & 20.684 & $<0.001^{*}$ \\
Post-test & 16.53 & 17 & 1.443 & & & \\
\hline
\end{tabular}

*Highly significant at $p<0.001$ level

staff nurses regarding safe handling of cancer drugs. The post-test was conducted after 7 days of pre-test.

\section{Results}

Table 1 shows distribution of level of knowledge regarding safe handling of cancer drugs during pre-test and post-test among staff nurses working in Mahatma Gandhi Medical College. During the pre-test out of 60 samples, $36(60 \%)$ had inadequate knowledge, 22 (36.7\%) had moderately adequate knowledge and 2 (3.3\%) had adequate knowledge and in the post-test 55 (91.7\%) had adequate knowledge and 5 (8.3\%) had moderately adequate knowledge.

Table 2 represents the mean, median, standard deviation, mean difference and paired " $t$ " value of the knowledge regarding safe handling of cancer drugs. The table reveals that the mean pre-test knowledge score was 8.62 and the post-test knowledge score was 16.53 ; it was higher than the pre-test. The standard deviation of the pre-test knowledge score was 2.969 and the post-test knowledge score was 1.443. The obtained paired " $t$ " value was 20.684 and it was highly significant at $p<0.001$ level.

It was inferred that the educational program on knowledge regarding safe handling of cancer drugs was highly effective. Hypothesis $\left(\mathrm{H}_{1}\right)$ was accepted. Hence, there is a significant difference in pre-test and post-test level of knowledge regarding safe handling of cancer drugs among staff nurses.

\section{ConCLUSION}

The main conclusion of the present study shows that the majority of staff nurses had inadequate knowledge during pre-test and post-test regarding the safe handling of cancer drugs. It reveals that the educational program was effective to improve the knowledge level of staff nurses. ${ }^{18}$

\section{Declaration of the Study Participants}

The author certifies that an appropriate consent forms should be obtained from all study participants. The study subjects understand that their names and initials will not be published and due efforts will make to conceal their identity, but anonymity cannot be guaranteed.

\section{References}

1. Chockalingam G. ASHP Technical Assistance Bulletin on Handling Cytotoxic and Hazardous Drugs. Am J Hosp Pharm 1990;47(2):1033-1049.

2. Chockalingam G. Brunner and Suddarth's A Textbook of Medical Surgical Nursing, 23rd ed. New Delhi: Jaypee Brothers Publisher; 2019. pp. 724-726.
3. Chockalingam G. Lewis's A Textbook of Medical Surgical Nursing, Second South Asia ed. Reed Elsevier India Private Limited; 2019. p. 267.

4. Sharma SK. Textbook of Nursing Research and Bio-Statistics, 1st ed. New Delhi: Reed Elsevier India Private Limited; 2005. pp. 99-103.

5. Rizzo T, Cloos R. Gale Encyclopedia of Cancer; 2002.

6. Ann M. Nursing Theories and its work, 3rd ed. Philadelphia: Mosby Publications; 2007. pp. 184-187.

7. Smith MC, Parker E. Nursing theories and nursing practice, 4th ed. Philadelphia: F. A. Davis Company; 2015. p. 23.

8. Polit H. Text book of Nursing Research, 2nd ed. New Delhi: Lippincott, Wiliams \& Wilkins Publications; 2013. pp. 97-103.

9. Rekhadevi PV, Sailaja N, Chandrasekhar M, Mahboob M, Rahman MF, Grover P. Genototoxicity Assessment In Oncology Nurses Handling Antineoplastic Drugs. Mutagenesis 2007 Nov;22(6):395-401. DOI: 10.1093/mutage/gem032.

10. Dranitsaris $G$, Johnston $M$, Poirier $S$, Schueller T, Milliken D, Green E, et al. A Systematic Review and Meta-Analysis of The Literature On Health Care Providers Who Work With Cancer Drugs At An Increased Risk For Toxic Events. J Oncol Pharm Pract 2005;11(2):69-78. DOI: 10.1191/1078155205jp155oa.

11. Kosgeroglu N, Ayranci U, Ozerdogan N, Demirustu C. Turkish Nurses Information About and Administration of Chemotherapeutic Drugs. J Clin Nurs 2006 Sep;15(9):1179-1187. DOI: 10.1111/j.13652702.2006.01305.x.

12. Polovich M, Martin S. Nurses Use of Hazardous Drug-Handling Precautions and Awareness of National Safety Guideline. Oncol Nurs Forum 2011 Nov;38(6):718-726. DOI: 10.1188/11.ONF.718-726.

13. Kyprianou M, Kapsou M, Raftopoulos V, Soteriades ES. Knowledge, attitudes and Beliefs of Cypriot Nurses on The Handling of Antineoplastic Agents. Eur J Oncol Nurs 2010 Sep;14(4):278-282. DOI: 10.1016/j.ejon.2010.01.025.

14. Martin S, Larson E. Chemotherapy-Handling Practices of Outpatient and Office-Based Oncology Nurses. Oncol Nurs Forum 2003 Jul-Aug; 30(4):575-581. DOI: 10.1188/03.ONF.575-581.

15. Mahboob M, Rahman MF, Rekhadevi PV, Sailaja N, Balasubramanyam A, Prabhakar PV, et al. Monitoring Of Oxidative Stress In Nurses Occupationally Exposed To Antineoplastic Drugs. Toxicol Int 2012 Jan;19(1):20-24. DOI: 10.4103/0971-6580.94510.

16. Baykal U, Seren S, Sokmen S. A Description of Oncology Nurses, Working Conditions in Turkey. Eur J Oncol Nurs 2009 Dec;13(5): 370-375. DOI: 10.1016/j.ejon.2009.04.004.

17. Mccarthy H. A Review of Educational Needs of The Nurses Administering Cancer Chemotherapy In Rural and Remote Areas Of Australia. Am J Nurs 2001;25(1):65-67.

18. Karpagam K, Mangalagowri P, Aruna S. Effectiveness of planned teaching programme on safe handling of chemotherapy drugs among staff nurses. Int J Pharma Bio Sci 2017;8(1):180-184.

19. Nwagbo SE, llesanmi RE, Ohaeri BM, Oluwatosin AO. Knowledge of chemotherapy and occupational safety measures among nurses in oncology units. J Clin Sci 2017;14(3):131-133. DOI: 10.4103/jcls. jcls_88_16. 